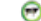

\title{
PHOTOSYNTHETIC PIGMENTS IN SHOOTS OF VACCINIUM CORYMBOSUM L. (CV. ELLIOTT)
}

\section{Yavorska Natalia*, Vorobets Natalia}

Danylo Halytsky Lviv National Medical University, Faculty of Pharmacy, Department of Pharmacognosy and Botany, Lviv, Ukraine

Received: 19. 7. 2019 Revised: 21. 11.2019 Published: 28. 11. 2019

Shoots of Vaccinium corymbosum L. (Ericaceae), which introduced in Ukraine are thought to be responsible for several therapeutic properties. Acetone (80 and 100\%), ethanol (96\%), and dyethyl ether extracts were prepared from aerial parts of $V$. corymbosum cv. Elliott in order to examine chlorophyll $a$ and $b$, and carotenoids content. The quantitative content of chlorophyll $a$ and $b$, and carotenoids in the shoots of $V$. corymbosum of the Elliott variety has been investigated and the dynamics of their seasonal accumulation, depending on the vegetation phase, has been analyzed. The content of pigments was determined spectrophotometrically at wavelengths that correspond to the absorption maxima of chlorophylls $a$ and $b$ and carotenoids for each solvent. For comparison, Vaccinium uliginosum $\mathrm{L}$. (bog bilberry) shoots were used, as an aboriginal European species of Ericaceae. It was established that the best solvent for extraction of chlorophylls in V. corymbosum shoots is $100 \%$ acetone, as compared to $96 \%$ ethanol and diethyl ether. The highest content of both chlorophylls was in the flowering and fruiting stages. The maximum values for chlorophylls $a$ and $b$ content were recorded in autumn period end of September-beginning of October (phase III of growing season): $78.57 \pm 2.02 \mathrm{mg} / 100 \mathrm{~g}$ DW for chlorophyll $a$, and $81.130 .72 \mathrm{mg} / 100 \mathrm{~g}$ DW for chlorophyll $b$. In the $80 \%$ acetone as extragent the maximum values for both chlorophylls were observed in Phase II of fruiting $73.24 \pm 0.27 \mathrm{mg} / 100 \mathrm{~g}$ DW for chlorophyll $a$ and $48.51 \pm 0.55 \mathrm{mg} / 100 \mathrm{~g}$ DW for chlorophyll $b$. In all the variants studied, the minimum value of chlorophylls $a$ and $b$ was observed in the IV winter growing season. The content of chlorophylls in the shoots of $\mathrm{V}$. corymbosum is higher compared to the V. uliginosum during fruiting period, and the total content of carotenoids in the $V$. corymbosum and $V$. uliginosum shoots was not significantly different at the fruiting stage.

Keywords: Vaccinium corymbosum L. cv. Elliott, shoot, chlorophyll, carotenoids

\section{Introduction}

Highbush blueberry (Vaccinium corymbosum L.) is a long-blooming deciduous shrub belonging to the section Cyanococcus, genus Vaccinium, heather family (Ericaceae). The record of the name of Vaccinium corymbosum derives from WCSP (data supplied on 2012-03-23) which

\footnotetext{
*Corresponding author: Natalia Yavorska, Danylo Halytsky Lviv National Medical University, Department of Pharmacognosy and Botany, Pekarska 69, 79010 Lviv, Ukraine $\triangle$ yavorska.natali@gmail.com
} 
reports it as an accepted name with original publication details: Sp. Pl. 350 1753., derived exclusively from North America, which is found in wild form in marshy regions north USA and Canada (Vander Kloet, 1980; Song and Hancock, 2011). In the ecological aspect, highbush blueberry belongs to the xeromorphic oligotrophs and obligates mycorrhiza species, as well as to plants with incompletely specialized flowering shoots (Pliszka, 2002). V. corymbosum is a plant that has a high commercial value and is cultivated worldwide. Species of highbush blueberries introduced and grown in Ukraine are outside their ecological optimum and are vulnerable to changes in environmental factors (Shlapak et al., 2013; Vasyuk, and Haritonova, 2016). A sensible indicator of the physiological state of plants is the quantitative and qualitative changes in the pigment complex, which is interesting and relevant for V. corymbosum. Herbal pigments are not only responsible for the absorption, transmission, and transformation of light energy into photosynthesis, but also biologically active sources for therapeutic applications, including antioxidant, antitumor, anti-inflammatory action, photothermal, photodynamic therapy (Wang and Wink, 2016; Park et al., 2018). It is known that chlorophylls and carotenoids correlate with phenolic compounds of plants, and also play an important role in the prevention of thalassemia and hemolytic anemia; and reduce the risk of cardiovascular disease (Niroula et al., 2019), exhibit antioxidant and immunomodulatory activity that prevents age disease, skin disease due to exposure to ultraviolet radiation, diabetes and some types of digestive tract cancers in human (Clotault et al., 2008; Bernal et al., 2010).

The aim of the study was to investigate the features of photosynthetic pigment accumulation (chlorophylls $a$ and $b$ and carotenoids) in shoots of V. corymbosum L. cv. Elliott and to trace their changes in different vegetation periods in order to evaluate the possibility of use as a medicinal plant raw material; to compare the pigment content in $V$. corymbosum and V. uliginosum shoots in the fruiting phase.

\section{Material and methodology}

\section{Plant material}

Shoots of Vaccinium corymbosum cv. Elliot grown on the experimental plot of 'Berry Partner' Ltd. in the village Sokilnyky of Lviv region of Ukraine were collected in the seasons 20172018. V. corymbosum plants were obtained by in vitro propagation on Woody Plant Medium (Yavorska et al., 2016). Collection of $V$. corymbosum c.v. Elliott plant materials, was carried out during flowering (I), fruiting period (II), in autumn after fruiting (III), the period preparation for winter rest (IV). Shoots of Vaccinium uliginosum (an native European species of the Ericaceae family) harvested during fruiting were used for comparison. The plant material was air-dried in the dark at a temperature of $22-24 \stackrel{\circ}{ } \mathrm{C}$ and ground to a powder before use.

\section{Extraction of photosynthetic pigments}

Pigments of airborne shoots of highbush blueberry were extracted with acetone (80 and 100\%), ethanol (96\%), diethyl ether. The content of pigments was determined spectrophotometrically (as described in Musienko et al., 2001). The optical density of the extract was determined at wavelengths that correspond to the absorption maxima of 
chlorophylls $a$ and $b$ and carotenoids for each extractant. Shredding of dry material carried mechanically (using a grinder), and then passed through sieves with pore diameter $2.5 \mathrm{~mm}$ and used for the extraction process. 100.00 or $200.00 \mathrm{mg}$ plant material was ground, placed in a porcelain mortar and triturated refilling $2-5 \mathrm{~mL}$ portions of chilled solvent in the presence of calcium carbonate $(0.2 \mathrm{~g})$. The extract obtained was centrifuged at $5.000 \mathrm{rpm}$ for 10 minutes. The supernatant was collected, and the precipitate resuspendable to discoloration. The extracts were combined, the volume was adjusted to 25 or $50 \mathrm{ml}$, and the optical density at the appropriate wavelength was determined using a solvent as a solution for comparison. Depending on the nature of the solvent used to extract the pigments, their concentration was calculated according to the corresponding equation.

\section{Determination of the total content of photosynthetic pigments}

The concentration of chlorophyll $a(\mathrm{Chl} a)$, chlorophyll $b(\mathrm{Chl} b)$, chlorophyll $a+b(\mathrm{Chl} a+b)$, and carotenoids were calculated according to the formulae. If $100 \%$ acetone was employed in pigment extracting, the optic density was defined in optimal $\lambda$ waves (in $\lambda=662 ; 644$; $440.5 \mathrm{~nm}$ ). The pigment concentration was estimated by Holm-Wettstein formula (Holm, 1954; Wettstein, 1957):

$$
\begin{gathered}
\mathrm{C}_{\mathrm{Chl} a}, \mathrm{mg} / \mathrm{L}=9.784 \cdot \mathrm{D}_{662}-0.990 \cdot \mathrm{D}_{644} \\
\mathrm{C}_{\mathrm{Chl} b} \mathrm{mg} / \mathrm{L}=21.426 \cdot \mathrm{D}_{644}-4.650 \cdot \mathrm{D}_{662} \\
\mathrm{C}_{\text {Chl }(a+b)}, \mathrm{mg} / \mathrm{L}=5.134 \cdot \mathrm{D}_{662}+20.436 \cdot \mathrm{D}_{644}
\end{gathered}
$$

Calculations were performed according to the formula proposed by Shlyk (Shlyk, 1968) too:

$$
\begin{gathered}
\mathrm{C}_{\mathrm{Chl} a^{\prime}} \mathrm{mg} / \mathrm{L}=11.7 \cdot \mathrm{D}_{662}-2.02 \cdot \mathrm{D}_{644} \\
\mathrm{C}_{\text {Chl } b}, \mathrm{mg} / \mathrm{L}=21.19 \cdot \mathrm{D}_{644}-4.54 \cdot \mathrm{D}_{662} \\
\mathrm{C}_{\text {Chl }(a+b)}, \mathrm{mg} / \mathrm{L}=7.14 \cdot \mathrm{D}_{662}+19.10 \cdot \mathrm{D}_{644}
\end{gathered}
$$

If $80 \%$ acetone was used for the extraction of pigments, the absorption was measured at $\lambda 665$, $663,649,646,470 \mathrm{~nm}$. The pigment concentration was estimated by the formula proposed by Vernon (Vernon, 1960):

$$
\begin{gathered}
\mathrm{C}_{\mathrm{Chl} a^{\prime}} \mathrm{mg} / \mathrm{L}=11.63 \cdot \mathrm{D}_{665}-2.39 \cdot \mathrm{D}_{649} \\
\mathrm{C}_{\mathrm{Chl} b^{\prime}} \mathrm{mg} / \mathrm{L}=20.11 \cdot \mathrm{D}_{649}-5.18 \cdot \mathrm{D}_{665} \\
\mathrm{C}_{\mathrm{Chl}(a+b)^{\prime}} \mathrm{mg} / \mathrm{L}=6.45 \cdot \mathrm{D}_{665}+17.72 \cdot \mathrm{D}_{649}
\end{gathered}
$$

The calculations were performed according to the formula proposed by Lichtentaller and Welburn (1983) too:

$$
\begin{aligned}
& \mathrm{C}_{\text {Chl } a^{\prime}} \mathrm{mg} / \mathrm{L}=12.21 \cdot \mathrm{D}_{663}-2.81 \cdot \mathrm{D}_{646} \\
& \mathrm{C}_{\text {Chl } b^{\prime}} \mathrm{mg} / \mathrm{L}=20.13 \cdot \mathrm{D}_{646}-5.03 \cdot \mathrm{D}_{663}
\end{aligned}
$$


Calculations of the content of chlorophylls and carotenoids in the extract, where $96 \%$ ethanol was used as a solvent, were carried out according to the formula proposed by Wintermans and de Mots (1965) aftermeasurement of absorbance at 649 and $665 \mathrm{~nm}$ :

$$
\begin{aligned}
& \mathrm{C}_{\mathrm{Chl} a^{\prime}} \mathrm{mg} / \mathrm{L}=13.70 \cdot \mathrm{D}_{665}-5.76 \cdot \mathrm{D}_{649} \\
& \mathrm{C}_{\mathrm{Chl} b}, \mathrm{mg} / \mathrm{L}=25.80 \cdot \mathrm{D}_{649}-7.60 \cdot \mathrm{D}_{665}
\end{aligned}
$$

Calculations of the content of chlorophylls and carotenoids in the extract, where $100 \%$ diethyl ether was used as an solvent, were carried out according to the formula proposed by Wintermans and de Mots (1965) after measurement of absorbance at 480, 642.5 and $660 \mathrm{~nm}$ :

$$
\begin{gathered}
\mathrm{C}_{\mathrm{Chl} a}, \mathrm{mg} / \mathrm{L}=9.93 \cdot \mathrm{D}_{660}-0.777 \cdot \mathrm{D}_{642.5} \\
\mathrm{C}_{\mathrm{Chl} b}, \mathrm{mg} / \mathrm{L}=17.6 \cdot \mathrm{D}_{642.5}-2.81 \cdot \mathrm{D}_{660} \\
\mathrm{C}_{\mathrm{Chl}(a+b)}, \mathrm{mg} / \mathrm{L}=7.12 \cdot \mathrm{D}_{660}+16.8 \cdot \mathrm{D}_{642.2} \\
\mathrm{C}_{\mathrm{Car}}, \mathrm{mg} / \mathrm{L}=\left(1,000 \cdot \mathrm{D}_{480}-0.52 \cdot \mathrm{C}_{\mathrm{Chl} a}-7.25 \mathrm{C}_{\mathrm{Chl} b}\right) / 226
\end{gathered}
$$

The results were recalculated and expressed in mg per g of dry matter. To calculate the content of pigments in the plant material in $\mathrm{mg} / \mathrm{g}$ of dry or fresh weight, according to following formula:

$$
A=C \cdot V / H \cdot 1,000
$$

where $A$ - content of pigments, $\mathrm{mg} / \mathrm{g}$ dry or fresh weight; $C$ - pigment concentration, $\mathrm{mg} / \mathrm{l}$; $\mathrm{V}$ - volume of extract, $\mathrm{ml}$ (25 or $50 \mathrm{ml}$ ); $\mathrm{H}$ - weight of plant material $(0.100-0.200 \mathrm{~g})$.

All extraction procedures were performed under subdued light to avoid pigment degradation. Values represent mean \pm SE $(n=5)$.

\section{Results and discussion}

Investigation of the content of pigments, namely chlorophylls, is an important indicator in plant physiology, biochemistry, ecology and has a taxonomic value. When applying plant raw materials for the manufacture of drugs or in the treatment of the use of teas or tinctures that make ex tempore it is important to know their composition, and hence the content of chlorophylls and carotenoids. For the initial screening of plant material, as well as for checking its quality in routine analyzes, rapid methods, in particular spectrophotometric, are most suitable. Determining the concentration of chlorophylls $a$ and $b$ in solution without separating them is difficult, however, existing differences in the absorption spectra, namely certain wavelengths where the absorption of one pigment significantly exceeds the absorption of another, allow quantitative determination of chlorophylls $a$ and $b$ without their separation. In this study we used acetone (100\%, 80\%), ethanol (96\%) and diethyl ether as solvents, which are effective extractants and provide close estimates of the content of chlorophylls (Ritchie, 2006). Table 1 presents the quantitative content of $\mathrm{Chl} a$, Chl $b, \mathrm{Chl} a+b$ in acetone and ethanol extracts of V. corymbosum shoots in different phenological periods and V. uliginosum L. (during fruiting). 
Table 1 Chlorophylls contents (mean \pm SD) in shoots of Vaccinium uliginosum L. and V. corymbosum L. cv. Elliott

\begin{tabular}{|c|c|c|c|c|}
\hline Plant material & $\begin{array}{c}\text { Phenological } \\
\text { phases* }\end{array}$ & $\begin{array}{c}\text { Chl } a \\
\text { (mg/100 g DW) }\end{array}$ & $\begin{array}{c}\text { Chl } b \\
\text { (mg/100 g DW) }\end{array}$ & $\begin{array}{c}\text { Chl } a+b \\
(\mathrm{mg} / 100 \mathrm{~g} \mathrm{DW})\end{array}$ \\
\hline \multicolumn{5}{|c|}{ In $100 \%$ acetone } \\
\hline \multicolumn{5}{|c|}{ according to Holm-Wettstein formulas } \\
\hline V. uliginosum & II & $29.60 \pm 0.83$ & $20.29 \pm 0.43$ & $49.88 \pm 0.43$ \\
\hline \multirow[t]{4}{*}{ V. corymbosum cv. Elliott } & I & $56.20 \pm 0.38$ & $12.94 \pm 0.15$ & $69.14 \pm 0.24$ \\
\hline & II & $63.98 \pm 0.46$ & $61.22 \pm 1.52$ & $125.13 \pm 1.98$ \\
\hline & III & $69.84 \pm 1.69$ & $81.13 \pm 0.72$ & $150.97 \pm 0.98$ \\
\hline & IV & $28.95 \pm 0.05$ & $11.73 \pm 0.04$ & $40.66 \pm 0.07$ \\
\hline \multicolumn{5}{|c|}{ according to Shlyk formulas } \\
\hline V. uliginosum & II & $33.91 \pm 0.99$ & $20.19 \pm 0.43$ & $54.1 \pm 0.59$ \\
\hline \multirow[t]{4}{*}{ V. corymbosum cv. Elliott } & I & $65.49 \pm 0.46$ & $13.03 \pm 0.14$ & $78.52 \pm 0.32$ \\
\hline & II & $72.47 \pm 0.59$ & $60.82 \pm 1.50$ & $133.35 \pm 2.08$ \\
\hline & III & $78.57 \pm 2.02$ & $80.54 \pm 0.71$ & $157.85 \pm 1.15$ \\
\hline & IV & $33.52 \pm 0.06$ & $11.71 \pm 0.02$ & $45.22 \pm 0.07$ \\
\hline \multicolumn{5}{|c|}{ In $80 \%$ acetone } \\
\hline \multicolumn{5}{|c|}{ according to Vernon formulas } \\
\hline V. uliginosum & II & $28.91 \pm 0.03$ & $17.22 \pm 0.03$ & $46.14 \pm 0.01$ \\
\hline \multirow[t]{4}{*}{ V. corymbosum cv. Elliott } & I & $29.02 \pm 1.31$ & $14.23 \pm 0.72$ & $43.26 \pm 0.59$ \\
\hline & II & $65.54 \pm 0.71$ & $48.51 \pm 0.55$ & $111.84 \pm 3.65$ \\
\hline & III & $38.89 \pm 0.15$ & $27.99 \pm 0.15$ & $66.92 \pm 0.06$ \\
\hline & IV & $29.83 \pm 0.45$ & $2.15 \pm 0.18$ & $31.99 \pm 0.27$ \\
\hline \multicolumn{5}{|c|}{ according to Lichtenthaler formulas } \\
\hline V. uliginosum & II & $29.81 \pm 0.73$ & $12.26 \pm 0.31$ & $42.07 \pm 0.61$ \\
\hline \multirow[t]{4}{*}{ V. corymbosum cv. Elliott } & I & $36.90 \pm 0.60$ & $5.04 \pm 0.26$ & $41.90 \pm 0.37$ \\
\hline & II & $73.24 \pm 0.27$ & $29.56 \pm 0.44$ & $102.60 \pm 0.36$ \\
\hline & III & $37.8 \pm 0.14$ & $24.05 \pm 0.09$ & $61.85 \pm 0.07$ \\
\hline & IV & $26.7 \pm 0.12$ & $2.39 \pm 0.05$ & $29.09 \pm 0.07$ \\
\hline
\end{tabular}

In $96 \%$ ethanol

according to Wintermans and de Mots formulas

\begin{tabular}{lcccc}
\hline V. uliginosum & II & $18.94 \pm 0.02$ & $25.73 \pm 0.02$ & $44.67 \pm 0.02$ \\
V. corymbosum cv. Elliott & I & $19.41 \pm 0.24$ & $20.87 \pm 0.23$ & $40.28 \pm 0.06$ \\
& II & $22.43 \pm 0.12$ & $6.32 \pm 0.05$ & $28.75 \pm 0.08$ \\
& III & $17.74 \pm 0.33$ & $26.64 \pm 1.22$ & $44.38 \pm 0.92$ \\
& IV & $16.79 \pm 0.15$ & $4.21 \pm 0.09$ & $21.01 \pm 0.06$ \\
\hline
\end{tabular}

Notes: *phases of vegetation: I - the period of flowering; II - the period of fruiting ; III - in autumn after fruiting period; IV - the period preparation for winter rest. 
Depending on the solvent, as shown in Table 1, the absolute values of chlorophyll content vary considerably. Thus, the content of $\mathrm{Chl} a$ in the $100 \%$ acetone extracts of $V$. corymbosum shoots in the phase I and phase III is 1.5-2.0 times higher compared to the corresponding $80 \%$ acetone extracts. Quantitative values of chlorophyll content in $96 \%$ ethanol extracts are significantly lower (2-3 times) compared to 80 and 100\% acetone extracts. The quantity of chlorophylls in the extracts of $V$. uliginosum and V. corymbosum in the use of diethyl ether as a solvent (Table 2 ) is significantly lower compared to acetone and ethanol extracts, respectively.

The results obtained indicate that the content of chlorophylls and carotenoids in shoots of blueberries c.v. Elliott increases from flowering phase to fruiting phase (Table 1, 2), regardless of the extractant used to determine them. Further increases in the content of chlorophylls and carotenoids in the autumn (late September - early October - phase III) were detected only when $100 \%$ acetone was used as the extractant: $78.57 \pm 2.02 \mathrm{mg} / 100 \mathrm{~g}$ DW for chlorophyll $a$ and $81.13 \pm 0.72 \mathrm{mg} / 100 \mathrm{~g}$ DW for chlorophyll $b$. Apparently, due to the accumulation of other groups of substances, $80 \%$ acetone and diethyl ether do not remove the entire amount of pigments from shoots in other investigated phases of highbush blueberry. The minimum content of chlorophylls $a$ and $b$ was observed at the beginning of winter (phase IV).

The content of chlorophylls $a$ and $b$ in shoots of bog bilberry was 2-3 times lower than that of highbush blueberry in the fruiting phase in all investigated variants, except for the use of diethyl ether as an extragent, where the absolute values of chlorophylls $a$ and $b$ were slightly different both investigated species.

Table 2 Chlorophylls and Carotenoid contents (mean \pm SD) in shoots of Vaccinium uliginosum L and V. corymbosum L. cv. Elliott

\begin{tabular}{lcccc}
\hline Plant material & $\begin{array}{c}\text { Chl } \boldsymbol{a} \\
(\mathbf{m g} / \mathbf{1 0 0} \mathbf{~ g ~ D W})\end{array}$ & $\begin{array}{c}\text { Chl } \boldsymbol{b} \\
(\mathbf{m g} / \mathbf{1 0 0} \mathbf{g} \text { DW })\end{array}$ & $\begin{array}{c}\text { Chl } \boldsymbol{a}+\boldsymbol{b} \\
(\mathbf{m g} / \mathbf{1 0 0} \mathbf{g ~ D W})\end{array}$ & $\begin{array}{c}\text { Car } \\
\text { (mg/100 g DW) }\end{array}$ \\
\hline \multicolumn{5}{c}{ In Diethyl ether } \\
\hline V. uliginosum II & $16.90 \pm 0.26$ & $18.20 \pm 0.09$ & $35.07 \pm 0.20$ & $4.39 \pm 0.12$ \\
V. corymbosum cv. Elliott & $16.68 \pm 0.25$ & $8.98 \pm 0.14$ & $25.65 \pm 0.14$ & $3.81 \pm 0.04$ \\
I & $18.85 \pm 1.94$ & $12.4 \pm 0.63$ & $31.23 \pm 0.06$ & $3.72 \pm 0.05$ \\
II & $19.37 \pm 1.80$ & $27.04 \pm 2.89$ & $44.95 \pm 1.11$ & $4.01 \pm 0.17$ \\
III & $11.66 \pm 0.31$ & $6.5 \pm 0.19$ & $18.26 \pm 0.24$ & $2.73 \pm 0.04$ \\
IV
\end{tabular}

Notes: *phases of vegetation: I - the period of flowering; II - the period of fruiting ; III - in autumn after fruiting period; IV - the period preparation for winter rest.

The content of carotenoids in the extracts of $V$. corymbosum shoots with ethyl ether was growing from the beginning of the vegetation till autumn and almost halved in the winter period of vegetation (IV period of winter rest). The increase in carotenoids content in $V$. corymbosum occurred during the growing season and decreased twice with the onset 
of winter rest (Table 2). The quantity of carotenoids in the extracts of $V$. uliginosum shoots is higher compared to V. corymbosum during fruiting (Phase II).

Since chlorophylls and carotenoids in food and herbal medicines are predominantly composed of lipophilic derivatives, and exhibits antioxidant, anti-mutagenic activity, and anti-inflammatory action, and could induction of apoptosis (Ferruzzi et al., 2007; Niyogi et al., 2015), it is important to know their content and to study the mechanisms of action.

\section{Conclusions}

According to the results of our studies, the following conclusions can be made: for extraction of chlorophylls from $V$. corymbosum shoots, the best solvent is $100 \%$ acetone, as compared to $96 \%$ ethanol and diethyl ether; the highest content of both chlorophylls was in the flowering and fruiting stages; the minimum values for chlorophylls $a$ and $b$ content were recorded in winter period; the content of chlorophylls in the shoots of $V$. corymbosum is higher compared to the $V$. uliginosum in fruiting period; the total content of carotenoids in the $V$. corymbosum and $V$. uliginosum shoots was not significantly different at the fruiting stage. This results will have great significance for comprehensive study and further use of V. corymbosum shoots as medicinal importance plant material.

\section{References}

BERNAL, J., MENDIOLA, J.A., IBANEZ, E., CIFUENTES, A. 2011. Advanced analysis of nutraceuticals. In J. Pharm. Biomed. Anal., vol. 55(14), p. 758-774. http://dx.doi.org/10.1016/i.jpba.2010.11.033

CLOTAULT, J., PELTIER, D., BERRUYER, R., THOMAS, M., BRIARD, M., GEOFFRIAU, E. 2008. Expression of carotenoid biosynthesis genes during carrot root development. In J. Exp. Bot, vol. 59(13), p. 3563-3573. http://dx.doi.org/10.1093/jxb/ern210

FERRUZZI, M.G., BLAKESLEE, J. 2007. Digestion, absorption, and cancer preventative activity of dietary chlorophyll derivatives. In Nutr. Res., vol. 27(1), p. 1-12. http://dx.doi.org/10.1016/j.nutres. 2006.12.003

HOLM, G. 1954. Chlorophyll mutations in barley. In Acta Agriculturae Scandinavica, vol. 4(1), p. 457471. http://dx.doi.org/10.1080/00015125409439955

LICHTENTHALER, K., WELBURN, A.R. 1983 Determination of total carotenoids and chlorophylls a and b of leaf extracts in different solvents. In Biochemical Society Transactions, vol. 11(5), p. 591-592. http://dx.doi.org/10.1042/bst0110591

MUSIENKO, M.M., PARSHYKOVA, T.V., SLAVNYY, P.S. 2001. Spektrofotometrychni metody $v$ praktytsi fiziolohiyi, biokhimiyi ta ekolohiyi roslyn [Spectrophotometric methods in the practice of physiology, biochemistry and plant ecology]. K.: Phytosotsiocenter, 200 p. [In Ukrainian].

NIROULA, A., KHATRI, S., TIMILSINA, R., KHADKA, D., KHADKA, A., OJHA, P. 2019. Profile of chlorophylls and carotenoids of wheat (Triticum aestivum L.) and barley (Hordeum vulgare L.) microgreens. In J. Food Sci. Technol., vol. 56(5), p. 2758-2763. http://dx.doi.org/10.1007/ s13197-019-03768-9

NIYOGI, K.K., WOLOSIUK, R.A., MALKIN, R. 2015. Photosynthesis. In Biochemistry and Molecular Biology of Plants. Editors: Buchanan B.B., Gruissem W., Jones R.L. John Wiley \& Sons; Hoboken, NJ, USA: p. 568-588. ISBN 978-0-470-71421-8

PARK, W.S., KIM, H.-J., DONG M.L., LIM, H., KIM, J., KWAK S.-S., KANG C.-M., FERRUZZI M.G., AHN, M-J. 2018. Two Classes of Pigments, Carotenoids and C-Phycocyanin, in Spirulina Powder and Their Antioxidant Activities. In Molecules., vol. 23(8), p. 2065. https://doi.org/10.7717/peerj.1879 
PLISZKA, K. 2002. Borówka wysoka. Praca zbiorowa, Warszawa: Państwowe Wydawnictwo Rolnicze i Leśne, 154 p. ISBN 83-09-01756-1 [In Polish].

RITCHIRE, R.J. 2006. Consistent sets of spectrophotometric chlorophyll equations for acetone, methanol and ethanol solvents. In Photosynth. Res., vol. 89(1), p. 27-41. http://dx.doi.org/10.1007/ s11120-006-9065-9 123

SHLAPAK, V.P., BALABAK, A.F., PYZH'YANOVA, A.A. 2013. Osoblyvosti prochodzennia phenolohichnych phaz introdukovanych sortiv chornyci vysokorosloi (Vaccinium corymbosum L.) v umovach Pravobereznoho Lisostepu Ukrainy [Features of phenological phases tranzition of introduced varietes of highbush blueberry (Vaccinium corymbosum L.) under the right-bank forest-steppe zone of Ukraine]. In Proceedings of the Forestry Academy of Sciences of Ukrain, vol. 11, p. 93-96. ISSN 1991-606X [In Ukrainian].

SHLYK, A.A. 19680 spectrophotometricheskom opredelenii chlorophyllov a i b [On spectrophotometric determination of chlorophylls a and b]. In Biokhimiia, vol. 33(2), p. 275-285. PMID: 5663910 [In Russian].

SONG, G.Q., HANCOCK, J.F. 2011. Vaccinium. In Wild Crop Relatives: Genetic, Genomic and Breeding Resource Editors: Chittaranjan Kole. Springer-Verlag Berlin Heidelberg, p. 197-221. https://doi. org/10.1007/978-3-642-16057-8 10

VANDER KLOET, S.P. 1980. The taxonomy of the highbush blueberry, Vaccinium corymbosum. In Canadian J. of Botany, vol. 58(10), p. 1187-1201. https://doi.org/10.1139/b80-148

VASYUK, E., HARITONOVA, I. 2016. Changes in acidity of soils under bluberry (Vaccinium corymbosum L.) using different substances for acidification. In Agrobiodiversity for Improving Nutrition, Health, and Life Quality, p. 471-474. ISBN 978-80-552-1586-0

VERNON, L.P. 1960. Spectrophotometric determination of chlorophylls and pheophytins in plant extracts. In Analytical Chemistry, vol. 32(9), p 1144-1150. https://doi.org/10.1021/ac60165a029

VON WETTSTEIN, D. 1957 Chlorophyll letale and der sub-mikroskopishe formweschselder plastiden. In Exp. Cell Research, vol. 12, p. 427-506. https://doi.org/10.1016/0014-4827(57)90165-9

WANG, E., WINK, M. 2016. Chlorophyll enhances oxidative stress tolerance in Caenorhabditis elegans and extends its lifespan. In Peer J, vol. 4, p. e1879. https://doi.org/10.7717/peerj.1879

WINTERMANS, J.E.G., DE MOTS, A. 1965. Spectrophotometric Characteristics of chlorophyll $a$ and $b$ and their phaeophytins in ethanol. In Biochimica et Biophysica Acta, vol. 109(2), p. 448-453. http:// dx.doi.org/10.1016/0926-6585(65)90170-6

YAVORSKA, N., LOBACHEVSKA, O., KHORKAVTSIV, Y., KYYAK, N. 2016. Microclonal propagation of the varieties of highbush blueberry Vaccinium corymbosum L. In Biotechnologia Acta, vol. 9(5), p. 3037. https://doi.org/10.15407/biotech9.05.030 